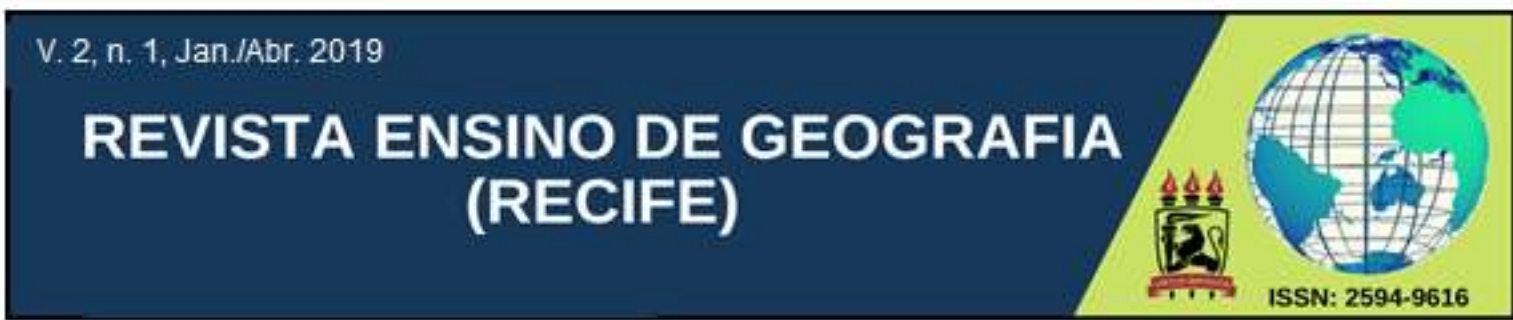

\title{
POSSIBILIDADES DIDÁTICAS DA GEOGRAFIA ESCOLAR A PARTIR DA TEMÁTICA DESASTRES NATURAIS
}

\author{
Leonardo Dirceu de Azambuja \\ Universidade Estadual de Maringá (UEM) \\ leonardodirceuazambuja@gmail.com \\ ORCID Id: http://orcid.org/0000-0002-2198-4171 \\ Osmar Rigon \\ Universidade Estadual de Maringá (UEM) \\ origon@uem.br \\ ORCID Id: http://orcid.org/0000-0003-1377-717X
}

Artigo recebido em 07/05/2019 e aceito em 18/06/2019

\begin{abstract}
RESUMO: Desastres naturais são temas da atualidade, pautada em eventos e ações relacionadas com as questões socioambientais do planeta Terra. Logo, a pertinência em ser também um conteúdo curricular na Educação Básica. O presente artigo objetiva refletir sobre possibilidades didáticas dessa inclusão. Para isso, com a finalidade de subsidiar as práticas de ensino-aprendizagem, busca-se inicialmente explicitar sobre os conceitos relacionados ao tema. A seguir é destacada a finalidade da escola em trabalhar com o conhecimento científico universal promovendo a interação desse saber e a realidade. No caso da Geografia Escolar esse desafio passa pela elaboração didática dos conteúdos relacionados com a natureza e ou com as relações socioespaciais. Para refletir sobre caminhos possíveis são explicitadas duas simulações. A primeira na forma de aprendizagem baseada em problemas com o tema da erosão e, a segunda na forma de unidade temática com o tema cidade resiliente.
\end{abstract}

Palavras chaves: Educação Básica; Ensino de Geografia; Desastres Naturais.

\section{DIDACTIC POSSIBILITIES OF SCHOOL GEOGRAPHY USING NATURAL DISASTERS AS A THEME}

\begin{abstract}
Natural disasters are a current theme due to events and actions related to the socioenvironmental issues of the Earth. Thus, it is relevant to make them also a curricular content of the Basic Education. Herein, a discussion about this inclusion is presented. Initially, the concepts related to the theme "Natural Disasters" are presented to support the practices of teaching-learning. Next, the purpose of the school to work with the universal scientific knowledge and merge it with the reality is highlighted. In the case of School Geography, this challenge includes didactic elaborations of the contents related to nature and/or socio-spatial relationships. To discuss possible alternatives of how to do that, two simulations are presented, one structured as problem-based learning (using erosion as a theme), and another as a thematic unit (using the theme resilient city).
\end{abstract}

Keywords: Basic Education; Geography Teaching; Natural disasters. 


\section{INTRODUÇÃO}

O destaque e a recorrência dos eventos compreendidos pela denominação de desastres naturais ou desastres com desencadeadores naturais torna pertinente a abordagem e a interpretação científica e política do tema em Conferências Mundiais e de ações que tratam de questões ambientais e do desenvolvimento sustentável do planeta Terra. Nesse sentido, pode ser indicada a definição, pelas Nações Unidas, dos anos 1990 como a Década Internacional para a Redução dos Desastres Naturais (DIRDN), ou ainda, ações globais como as diretrizes e objetivos estabelecidos pelo Marco de Ação de Hyogo (2005-2015) e pelo Marco de Ação de Sendai (2015-2030), dentre outras.

No Brasil, mesmo que as questões relacionadas com os desastres naturais estivessem presentes em ações localizadas regionalmente já em décadas anteriores, pode-se datar a Constituição de 1988, como momento em que essa preocupação assume abrangência nacional. A partir desse período são implementadas políticas públicas tais como a criação do Sistema Nacional de Proteção e Defesa Civil (SINPDEC) e do Conselho Nacional de Proteção e Defesa Civil (CONPDEC), Lei $\mathrm{n}^{\mathrm{o}}$ 12.608, de 12 de abril de 2012. Incluem-se nessas definições legais, indicações e implementação de ações educacionais e preventivas relacionadas com o tema.

É nesse contexto que o conteúdo do presente artigo assume atualidade e torna-se também necessidade. Na primeira parte, busca-se explicitar sobre o conceito de desastre natural, os tipos e classificações quanto a intensidade, origem, evolução, duração e sobre as ações e políticas de prevenção desenvolvidas pela sociedade. As definições conceituais são referências necessárias, para reflexão aqui proposta, de inclusão dessa temática como conteúdo escolar. A segunda parte do texto faz a inserção do tema, considerando a finalidade ou centralidade curricular da escola em tratar da apropriação, pelos sujeitos, do conhecimento científico universal. Nas terceira e quarta partes, o propósito é o de aproximar o tema com as práticas de ensino-aprendizagem da Geografia Escolar. Objetiva-se exemplificar ou simular práticas relacionadas com os estudos da natureza e das relações socioespaciais, contemplando o conjunto de conhecimentos da Geografia Física e da Geografia Humana. São então apresentadas simulações didáticas com a intencionalidade de subsidiar a reflexão por parte de docentes da Educação Básica e da aplicação recriada das proposições na escola. 


\section{SOBRE O CONCEITO DE DESASTRES NATURAIS}

No decorrer da história, com o surgimento do Homo Sapiens moderno, há pelo menos 150 mil anos, a Terra foi habitada em um espaço de tempo relativamente curto. Com o desenvolvimento da linguagem, o domínio do fogo e a habilidade de construir e manusear ferramentas diversas e mais recentemente no período Neolítico, iniciado a cerca de 8.000 a.C, com o desenvolvimento da agricultura e da pecuária surgem formas organizadas de grupos sociais, o que oportunizou mudanças significativas no meio socioambiental, destacando-se a aceleração do crescimento populacional. Desde então, o ser humano vem travando duras batalhas no sentido de se integrar à dinâmica da natureza, bem como conhecê-la, compreendêla e modificá-la de modo a possibilitar o uso, que se deseja sustentável, dos recursos disponibilizados.

O planeta Terra tem sua própria dinâmica e com ela a ocorrência de eventos naturais diversos. São próprios dessa dinâmica os fenômenos endógenos, associados ao tectonismo, como os abalos sísmicos (terremotos, tsunamis) e atividades vulcânicas, bem como os exógenos, com destaque para os de origem climática: chuvas em excesso com capacidade de provocar enchentes, inundações, alagamentos, processos erosivos e escorregamentos, colapsos e subsidência de solos, secas extremas, vendavais, tempestades, tornados, furacões etc. Tais fenômenos podem resultar em grandes alterações na superfície terrestre, por vezes modificando-a em definitivo. Assim, é de se esperar que tais eventos interfiram na vida de populações humanas em menor ou maior escala e eventualmente o fazem agravados, por conta do crescimento populacional, sobretudo em áreas suscetíveis, fortemente adensadas, ocorrendo o que é denominado como desastres naturais.

E o que se pode entender por desastres? Eles podem ser definidos como:

Resultado de eventos adversos, naturais ou provocados pelo homem, sobre um ecossistema (vulnerável), causando danos humanos, materiais e/ou ambientais e consequentes prejuízos econômicos e sociais. Os desastres são quantificados, em função dos danos e prejuízos, em termos de intensidade, enquanto que os eventos adversos são quantificados em termos de magnitude. A intensidade de um desastre depende da interação entre a magnitude do evento adverso e o grau de vulnerabilidade do sistema receptor afetado. (CASTRO, 1998. p. 57)

Já a denominação desastres quando acrescida do adjetivo naturais identifica situações definidas por Tobin e Montz (1997); Marcelino (2008) apud Tominaga (2009, p. 14) "como resultado do impacto de fenômenos naturais extremos ou intensos sobre um sistema social, 
causando sérios danos e prejuízos que excede a capacidade da comunidade ou da sociedade atingida em conviver com o impacto."

Para a UN-ISDR (United Nations Strategy for Disaster Risk Reduction), secretaria da ONU, criada em 1999, com a incumbência de facilitar a implementação da Estratégia Internacional para a Redução de Desastres (ISDR) "Não existe desastre 'natural', apenas riscos naturais". A publicação da UN-ISDR (2004) define risco como "a probabilidade de consequências prejudiciais, ou danos esperados (morte, ferimentos a pessoas, prejuízos econômicos etc.) resultantes da interação entre perigos naturais ou induzidos pela ação humana e as condições de vulnerabilidade".

Ainda, segundo a UN-ISDR:

\begin{abstract}
A gravidade de um desastre depende de quanto impacto um perigo tem na sociedade e no meio ambiente. A escala do impacto, por sua vez, depende das escolhas que fazemos para nossas vidas e para o meio ambiente. Essas escolhas estão relacionadas a como cultivamos nossa comida, onde e como construímos nossas casas, que tipo de governo temos, como funciona nosso sistema financeiro e até o que ensinamos nas escolas. Cada decisão e ação nos torna mais vulneráveis a desastres - ou mais resilientes a eles.
\end{abstract}

A Redução do Risco de Desastres (RRD) visa reduzir os danos causados por desastres naturais, como terremotos, inundações, secas e ciclones, através de uma ética de prevenção. Reduzir os riscos de desastres por meio de esforços sistemáticos para analisar e reduzir seus fatores causais, reduzir a exposição a perigos eminentes, diminuir a vulnerabilidade de pessoas e lugares, promover um gerenciamento inteligente da Terra e do meio ambiente e melhorar a prontidão e alerta precoce para eventos adversos são objetivos a serem perseguidos.

Por conta das novas e eficientes formas de comunicação, atualmente o tema desastres naturais se faz presente e com maior frequência, no cotidiano das pessoas. Esses acontecimentos são diretamente responsáveis por grandes perdas de vidas, além de danos econômicos, sociais e ambientais.

Os desastres podem se diferenciar entre si quando se considera: a intensidade, a origem, evolução e a duração. Sobre esses fatores:

a) Intensidade - a avaliação da intensidade do desastre é fundamental, sobretudo, no que tange ao planejamento de resposta e recuperação do local atingido, já que todo o pósdesastre, especialmente o socorro às vítimas, dependem da intensidade dos danos e 
prejuízos provocados. O Quadro a seguir apresenta de maneira didática tal classificação. (Kobyiama, 2006, p. 8).

b)

Quadro 1: Classificação dos desastres em relação à intensidade.

\begin{tabular}{|c|c|c|}
\hline Nível & Intensidade & Situação \\
\hline I & $\begin{array}{l}\text { Desastres de pequeno porte, onde os } \\
\text { impactos causados são pouco importantes e } \\
\text { os prejuízos pouco vultosos. } \\
\text { (Prejuízos } \leq \mathbf{5 \%} \text { do PIB municipal) }\end{array}$ & $\begin{array}{l}\text { Facilmente superável com os recursos do } \\
\text { município. }\end{array}$ \\
\hline II & $\begin{array}{l}\text { De média intensidade, onde os impactos são } \\
\text { de alguma importância e os prejuízos são } \\
\text { significativos, embora não sejam vultosos. } \\
(\mathbf{5 \%}<\text { Prejuízos } \leq \mathbf{1 0 \%} \text { do PIB) }\end{array}$ & $\begin{array}{l}\text { Superável pelo município, desde que } \\
\text { envolva uma mobilização e administração } \\
\text { especial. }\end{array}$ \\
\hline III & $\begin{array}{l}\text { De grande intensidade, com danos } \\
\text { importantes e prejuízos vultosos. } \\
(\mathbf{1 0 \%}<\text { Prejuízos } \leq \mathbf{3 0 \%} \text { do PIB })\end{array}$ & $\begin{array}{l}\text { A situação de normalidade pode ser } \\
\text { restabelecida com recursos locais, desde } \\
\text { que complementados com recursos } \\
\text { estaduais e federais. } \\
\text { (Situação de Emergência - SE) }\end{array}$ \\
\hline IV & $\begin{array}{l}\text { Com impactos muito significativos } \\
\text { prejuízos muito vultosos. } \\
\text { (Prejuízos }>\mathbf{3 0 \%} \text { do PIB) }\end{array}$ & $\begin{array}{l}\text { Não é superável pelo município, sem que } \\
\text { receba ajuda externa. Eventualmente } \\
\text { necessita de ajuda internacional. } \\
\text { (Estado de Calamidade Pública - ECP) }\end{array}$ \\
\hline
\end{tabular}

Ainda, de acordo com Kobyiama (2006, p. 9), nos casos em que o município não conseguir restabelecer sua funcionalidade e necessitar de apoio do governo estadual ou federal deve preencher o formulário ADAVAN (Avaliação de Danos) e enviá-lo com outros documentos necessários à Defesa Civil Estadual que homologará ou não a situação de SE (Situação e Emergência) ou ECP (Estado de Calamidade Pública) decretada pelo município. O formulário ADAVAN é o registro oficial de desastres adotado no Brasil.

c) Origem - também denominada causa primária do agente causador, este critério se caracteriza por três tipos (CASTRO, 1999): os desastres naturais, aqueles provocados por eventos/fenômenos naturais que independem da ação antrópica, são exemplos: chuvas intensas, causando inundações, alagamentos, escorregamentos, erosões; vendavais, furacões e tornados, além de tsunamis, tempestades de neve, etc. Os desastres antropogênicos ou humanos, que são aqueles resultantes da ação ou omissão humana, tais como: rompimentos de barragem, acidentes de trânsito, incêndios, contaminações da água (rios, lagos, mares) e da atmosfera por produtos 
químicos. E os desastres mistos aqueles que através da ação ou omissão humana, contribuem para intensificar e/ou agravar os desastres de origem natural.

d) Evolução - Segundo Castro (1999), são três tipos de desastres associados à evolução, são eles: os desastres súbitos, que se caracterizam pela rapidez com que evoluem, tais como inundações bruscas e os tornados; os desastres graduais que tem sua evolução por etapas de agravamento progressivo, como as inundações graduais e as secas; os de somação de efeitos parciais, que são os caracterizados pela ocorrência de numerosos acidentes semelhantes, que quando somados, tem grandes impactos, exemplo deste tipo são os acidentes de trânsito e de trabalho.

e) Duração - quanto à duração os desastres naturais se classificam em dois tipos: episódicos e crônicos (SIDLE et al, 2004). Os episódicos como terremotos, tsunamis, tornados, erupções vulcânicas, destacam-se pela sua magnitude e rapidez. Já os crônicos como os processos erosivos do solo, geram problemas e prejuízos ambientais em longo prazo, podendo contribuir para a arenização e desertificação, assoreamento de rios e ainda escorregamentos e inundações.

O gerenciamento de desastres naturais (GDN) constitui uma importante ferramenta a serviço de uma gestão comprometida em prevenir, reduzir e controlar de maneira permanente o risco de desastres. Nas ocorrências de grande amplitude são consideradas oito etapas na composição do gerenciamento de desastres, são elas: Prevenção, Mitigação, Preparação, Alerta, Resposta, Reabilitação, Reconstrução e Desenvolvimento. Essas etapas se fazem presentes nos três momentos do desastre: antes, durante e após. O quadro a seguir (MARCHIORI-FARIA \& SANTORO, 2009, p. 163) apresenta de forma resumida as atividades de gerenciamento de riscos e respostas a desastres.

Quadro 2: Atividades de gerenciamento de riscos e respostas a desastres.

\begin{tabular}{|c|c|c|}
\hline & Durante o desastre & Apos o desas \\
\hline $\begin{array}{l}\text { Prev } \\
\text { ocor }\end{array}$ & \multirow{3}{*}{$\begin{array}{l}\text { Atividades de resposta ao } \\
\text { desastre: são aquelas que se } \\
\text { desenvolvem no período de } \\
\text { emergência ou imediatamente } \\
\text { após ocorrido o evento. Podem } \\
\text { envolver ações de evacuação, } \\
\text { busca e resgate, de assistência e } \\
\text { alívio à população afetada e ações }\end{array}$} & \multirow{3}{*}{$\begin{array}{l}\text { Reabilitação: período de } \\
\text { transição que se inicia ao final } \\
\text { da emergência e no qual se } \\
\text { restabelecem os serviços vitais } \\
\text { indispensáveis e os sistemas } \\
\text { de abastecimento da } \\
\text { comunidade afetada. } \\
\text { Reconstrução: caracteriza-se }\end{array}$} \\
\hline $\begin{array}{l}\text { Mitigação: pretende minimizar o } \\
\text { impacto do mesmo, } \\
\text { reconhecendo que muitas vezes } \\
\text { não é possível evitar sua } \\
\text { ocorrência. }\end{array}$ & & \\
\hline Preparação: estrutura a resposta & & \\
\hline
\end{tabular}




\begin{tabular}{|l|l|l|l|}
\hline $\begin{array}{l}\text { Alerta: corresponde à } \\
\text { notificação formal de um perigo } \\
\text { iminente. }\end{array}$ & $\begin{array}{l}\text { que se realizam durante o período } \\
\text { em que a comunidade se encontra } \\
\text { desorganizada e os serviços } \\
\text { básicos de infraestrutura não } \\
\text { funcionam. }\end{array}$ & $\begin{array}{l}\text { pelos esfos para reparar a } \\
\text { infraestrutura danificada e } \\
\text { restaurar o sistema de } \\
\text { produção, revitalizar a a } \\
\text { economia, buscando alcançar } \\
\text { ou superar o nível de } \\
\text { desenvolvimento prévio ao } \\
\text { desastre. }\end{array}$ \\
\hline
\end{tabular}

No Brasil, a Defesa Civil Nacional (BRASÍLIA, 2007, apud TOMINAGA; SANTORO; AMARAL, 2009, p. 163), adota em suas ações de redução de desastres etapas definidas como de prevenção, de preparação para emergências e desastres, de resposta e, de reconstrução. A seguir algumas indicações sobre cada uma dessas etapas.

a) Prevenção - como ação de prevenção se considera duas etapas: A primeira é a Avaliação de Riscos, na qual ocorre a identificação dos processos perigosos, indicação dos locais ameaçados, quantificação e estabelecimento de prioridades que visa a elaboração de banco de dados e de mapas temáticos sobre ameaças, vulnerabilidades e riscos de desastres a exemplo das cartas geotécnicas, mapas de suscetibilidade, cadastramento e zoneamento de risco. A segunda consiste na Redução de Riscos, que objetiva diminuir a magnitude dos processos de riscos e para isso se adota dois conjuntos de medidas preventivas: as medidas não-estruturais, que são as associadas ao planejamento do uso e ocupação do solo, em função da definição das áreas de risco, como os planos de contingência e sistemas de alertas. Já as medidas estruturais contemplam as obras de engenharia como obras de contenção em taludes; diques, barragens, controles de inundações, erosões etc.

b) Preparação para Emergências e Desastres - etapa encarregada de potencializar as ações preventivas, de resposta e reconstrução através de projetos, tais como: Desenvolvimento Institucional; de Recursos Humanos; Científicos e Tecnológicos; Mudança Cultural; Motivação e Articulação Empresarial; Informações e Estudos Epidemiológicos sobre Desastres; Monitoramento, Alerta e Alarme; Planejamento Operacional e de Contingência; Planejamento de Proteção de Populações contra Riscos de Desastres; Mobilização; Aparelhamento e Apoio Logístico.

c) Resposta - corresponde basicamente às ações práticas de: Socorro às vítimas; Assistência às populações com atividades de logística, assistenciais e promoção de saúde; Reabilitação do cenário do desastre, como avaliação de danos, vistoria e 
elaboração de laudos técnicos, desobstrução e remoção de escombros, sepultamento, limpeza, descontaminação, desinfecção e desinfestação do ambiente, recuperação de unidades habitacionais de baixa renda.

d) Reconstrução - Esta fase tem por tarefa restabelecer os serviços públicos, a economia da área atingida, o moral social e o bem-estar da população e para isso se deve recuperar os ecossistemas, reduzir as vulnerabilidades, promover o ordenamento do uso e ocupação do solo, realocar as populações para áreas de menor risco, objetivando voltar à normalidade bem como a prevenção de novos desastres.

A síntese aqui apresentada sobre o tema desastres naturais objetiva situar algumas referências conceituais e de ações implementadas por agentes públicos e ou da sociedade civil com a finalidade de contribuir e orientar as atividades de ensino-aprendizagem, objeto de reflexão do presente artigo. No desenvolvimento das atividades escolares certamente será necessário buscar complementações conforme a pertinência de cada singularidade do conteúdo a ser trabalhado.

\section{DESASTRES NATURAIS E A GEOGRAFIA ESCOLAR}

A centralidade ou a função curricular da escola corresponde a missão de oportunizar para as pessoas o acesso ao saber científico elaborado e considerando essa finalidade como atendimento de um direito da cidadania. Mas a escola, sem perder esse foco curricular, é também um espaço de vivências e frequentemente instigada para participar de demandas comunitárias, tais como, campanhas beneficentes, ações de prevenção à saúde, de educação ambiental, de educação para o trânsito e de ações coordenadas pela Defesa Civil relacionadas com o tema dos desastres naturais.

Essas demandas comunitárias podem em algum tempo e espaço interferir nos estudos curriculares na medida em que adentram a escola na condição de atividades não curriculares. É frequente falas de docentes indicando o fato de não ter conseguido completar adequadamente sua aula em consequência do envolvimento dos alunos com citadas demandas. Coloca-se então a questão: como incluir ou integrar essas ações com os conteúdos e as atividades curriculares? Ou ainda, como aproveitar o contexto ou a motivação dessas demandas para articular o estudo de conteúdos disciplinares? 
Refletir e projetar práticas curriculares específicas relacionadas com cada uma dessas situações, aproveitando ou potencializando os ambientes criados, é tarefa a ser planejada no cotidiano de cada escola. O tema em pauta no presente artigo está referido as ações da Defesa Civil na escola. Ao par das instruções repassadas pelos especialistas para a comunidade escolar com vistas a prevenção e antecipação de providências visando a redução de riscos e danos em eventuais eventos naturais e ou humanos, podem ser projetados estudos disciplinares ou interdisciplinares com as temáticas ali identificadas.

A informação é um dos principais instrumentos de prevenção de riscos e danos relacionados com os desastres naturais. A informação científica oportunizada pelo ensinoaprendizagem é também uma parte fundamental.

[...] a sociedade espera que a escola como instituição social encarregada pela formação sistemática de crianças e jovens mobilize, a tempo e hora, o conhecimento científico, tecnológico, matemático, físico, químico, geográfico, histórico, informático capazes de criarem uma consciência a favor da preservação do ambiente e, assim, aguçar a capacidade de prevenir e antecipar a luta contra fenômenos naturais e humanos de consequências graves. (VALE, 2017, p. 134).

A informação está disponível em todas as mídias, mas é preciso promover o acesso e, principalmente, estabelecer uma relação qualificada dos alunos com as informações. A escola é o lugar no qual a informação é apropriada, organizada, sistematizada, constrói-se enquanto conhecimento escolar e assume a finalidade informativa e prioritariamente formativa dos sujeitos.

\begin{abstract}
A educação tem e terá cada vez mais relevância na formação estratégica do homem do século XXI. Na pretensa "sociedade do conhecimento e da informação" do mundo globalizado e da terceira era industrial, precisaremos investir na melhoria e na ampliação da educação, permitindo o acesso ao conhecimento científico e tecnológico que possibilite à sociedade conhecimento aprofundado e relacional dos fatos histórico-sociais e dos fenômenos físicos que permitam entender e agir em prol da sociedade resiliente e sustentável. (JUNIOR, MAGNONI e FIGUEIREDO, 2017, p. 187-188).
\end{abstract}

A Geografia Escolar inclui o estudo da dinâmica ou dos fenômenos que produzem as paisagens naturais e, também, dos eventos que expressam a complexidade socioespacial, interpretando as conexões existentes nos objetos e nas ações naturais e humanizadas. Para isso a atualidade do debate relacionado com a renovação didática da escola e, em particular da Geografia, aponta na perspectiva de um ensino-aprendizagem que articule conhecimento, realidade e sujeitos. 
Essa didática específica e disciplinar precisa ser desenvolvida por meio de metodologias cooperativas e problematizadoras e que propõe o estudo de temas elaborados na interação realidade e ciência. As formas organizativas já conhecidas no campo da Didática são as alternativas que precisam ser assumidas. Projetos de trabalho, aprendizagem baseada em problemas, estudo do meio, unidade temática são as formas a partir das quais podem ser planejadas as sequências de aulas, com foco em objetos de aprendizagem ainda mais específicos.

Portanto, diante da essencialidade em assegurar o conhecimento geográfico na formação intelectual do aluno (a) cidadão(ã) crítico(a), da necessidade em entender a interrelação sociedade e fenômenos naturais e antrópicos e, ainda, em dar maior significado/importância à geografia escolar é que conteúdos relacionados com a questão dos desastres naturais ou desastres com desencadeadores naturais podem ser inclusos nas práticas de ensino-aprendizagem dessa disciplina. Nos itens a seguir são apresentadas, com a finalidade de subsidiar a reflexão, possibilidades docentes com destaque para temas com foco no estudo da natureza e ou da sociedade.

\section{TEMAS PARA O ENSINO DA NATUREZA PELA GEOGRAFIA}

Os avanços nas tecnologias de informação e comunicação significaram a ampliação dos conhecimentos sobre a natureza, exigindo maior especialização científica disciplinar no campo das denominadas ciências naturais. Tem-se então a definição de objetos e métodos específicos para os estudos de geologia, pedologia, geomorfologia, climatologia, hidrologia, oceanografia, astronomia, biologia e, também, para a Geografia Física, para citar os campos relacionados com os conteúdos escolares.

O foco desta parte do artigo é sobre a Geografia Física e se pertinente a dimensão interdisciplinar com os demais objetos específicos. A paisagem natural resulta da combinação espacialmente localizada de elementos naturais, tais como, rochas, tipos de solos, clima, flora, fauna e água, considerando também o tempo, a dinâmica ou o movimento do todo, natureza.

Na escola ou nos manuais didáticos de Geografia os conteúdos são apresentados em unidades e ou capítulos específicos de cada uma dessas especialidades e ou de forma conjunta. Ou ainda, em unidades e capítulos sobre o estudo dos domínios naturais nos quais as paisagens naturais podem ter uma leitura abrangente e integrada. 
A prática de ensino da Geografia Física é objeto de crítica quando associada com a questão da dicotomia física X humana na forma trabalhada pela Geografia Escolar entendida com "tradicional”. Mas o estudo da natureza pela Geografia é uma necessidade didática para a apropriação da capacidade de interpretação geográfica da realidade. A superação da citada dicotomia se dá no momento do estudo geográfico de um lugar, região, país ou continente. Nos estudos localizados espacialmente é que a dimensão sociedade e natureza precisa ser incluída enquanto espaço geográfico. Aí sim se estuda ou se ensina o processo de transformação do meio natural em meio social, em espaço geográfico enquanto totalidade socioespacial.

Dito isso, cabe abordar a dimensão didática do conteúdo escolar associado a uma perspectiva de ensino-aprendizagem temática e problematizadora, identificada com o paradigma do ensino-pesquisa. Os eventos naturais, conforme explicitados em item anterior podem ser desencadeadores de desastres naturais na medida em que atingem populações humanas. A ideia é trabalhar o conteúdo sobre a natureza relacionado com os possíveis temas instigados com a questão ou a referência dos desastres naturais.

O conhecimento da dinâmica da natureza a ser desenvolvido na forma de conteúdos escolares pode contribuir para a prevenção de desastres.

\footnotetext{
Prevenir desastres naturais exige a eficiente divulgação dos mecanismos que regem os processos naturais extremos. Assim, é extremamente importante discutir conceitos e propor atividades que favoreçam o uso de conceitos e o ensino de conteúdos relacionados à Geografia Física desde a escola básica. A noção de complexidade envolvida na organização dos sistemas geomorfológicos, por exemplo, inclui as noções de ajuste entre os elementos e de estabilidade relativa e dinâmica. (AFONSO, 2015, p. 192).
}

A apropriação dos conteúdos escolares vai instrumentalizar os alunos e, por extensão, os demais sujeitos da comunidade para identificação de situação de vulnerabilidade e risco. Compreender o porquê determinada área pode apresentar ou não uma situação instável e se apresenta condições degradadas, seja pela ação antrópica e ou natural é um saber pertinente. Reafirma-se então o entendimento de centralidade curricular nos saberes da ciência, tendo o estudo das ações de prevenção e mitigação de riscos como componente instigador do ensinoaprendizagem.

Fazer a aproximação didática, relacionando os eventos desencadeadores de desastres naturais e possíveis temas para serem trabalhados na forma de projetos de trabalho, aprendizagem baseada em problemas, estudo do meio ou unidade temática pode ser a opção 
de estudo. Com a finalidade de subsidiar a reflexão aqui proposta, são apresentadas algumas situações possíveis.

A existência de problemas localizados de erosão poderá ser o mote para o desenvolvimento do ensino-aprendizagem. A erosão laminar ou linear resulta da conjugação de fatores relacionado ao clima, cobertura vegetal, tipo de solo e declividade do relevo. No caso da erosão linear os seus efeitos se dão na forma de sulcos, ravinas e ou boçorocas. (Santoro, 2009) A didatização da situação de aprendizagem pode ser escolhida dentre as formas acima indicadas. Para o exercício aqui sugerido, opta-se pela alternativa da aprendizagem baseada em problemas para elaborar a simulação a seguir:

1. Escolha e contextualização da realidade e do problema que será objeto de estudo. Há um problema de erosão localizado próximo da escola e ou de conhecimento da comunidade escolar. A dinâmica de sala de aula pode ser iniciada com o uso de imagens, coletadas virtualmente, do local e ou de outros locais como estratégia para iniciar o diálogo sobre o tema, com a finalidade de elaborar um diagnóstico preliminar e encaminhar a delimitação do problema para o estudo.

2. Nesse primeiro diagnóstico e delimitação do problema são também identificadas necessidades de conhecimento específico para o entendimento da realidade e as possíveis alternativas de solução ou mitigação. Define-se a seleção e a organização de conteúdos conceituais e informativos e as fontes de estudo e pesquisa, ou seja, os recursos didáticos.

3. Num terceiro momento distribuem-se as atividades de estudo-pesquisa, organizando grupos de alunos e ou atribuições individuais. Essa é a etapa de reunir informações, elaborar interpretações associando os fatores climáticos, vegetação, solo e relevo e, se for o caso, as intervenções antrópicas que produziram as alterações no meio natural.

4. O conhecimento acumulado até essa etapa possibilita a elaboração de hipóteses que possam encaminhar soluções ou a mitigação do problema. Projetam-se atividades e recursos didáticos tais como: maquete ou croqui de perfil de solo, representação da área em estudo por meio de mapas e ou maquetes, uso do Google Earth, textos e ou imagens analisando o processo de ocupação do lugar, as transformações socioculturais e econômicas e as consequentes transformações no meio natural. 
5. As elaborações projetadas e executadas no momento anterior serão agora objeto de exposição ou de socialização dos resultados, ampliando a análise e sugerindo recomendações e possíveis ações, tais como, práticas de construção de terraços, maior cobertura vegetal, dentre outras. O processo de ensino-aprendizagem finaliza com a avaliação coletiva e ou individual dos resultados.

É oportuno observar que no desenvolvimento desse processo de ensino-aprendizagem os conteúdos curriculares relacionados com clima, vegetação, solos e relevo estarão em pauta. O estudo mesmo que realizado com a finalidade de responder ao problema localizado poderá ou deverá contemplar a universalidade do conhecimento na medida em que precisará abordar conceitualmente as informações. Por meio de fontes bibliográficas virtuais e ou impressas, de imagens, das representações cartográficas, do conhecimento docente e de pessoas que poderão ser convidadas para conversar com os alunos em sala de aula e ou serem entrevistadas, e ainda, pela realização de aula a campo, a Geografia Escolar estará sendo efetivada. E, dessa forma o problema em estudo que aborda o tema de desastre natural será compreendido numa dimensão de totalidade.

\section{TEMAS PARA O ENSINO DA SOCIEDADE PELA GEOGRAFIA}

Dentre os conteúdos atribuídos a Geografia destaca-se a Geografia Urbana que ao ser tratada no ensino fundamental e médio inclui o estudo do espaço urbano, ou seja, a cidade como conteúdo escolar. Muitas são as possibilidades de organização didática para esse conteúdo, porém, neste momento o objetivo é relacionar com o tema dos desastres naturais, os quais deixam de ser naturais quando vistos também na perspectiva dos riscos para as populações dos lugares.

Ao par das ações preventivas e educativas coordenadas e ou apoiadas pela Defesa Civil, envolvendo as comunidades escolares, a ideia aqui é a de tratar a questão desastres naturais enquanto conteúdo geográfico e sem a preocupação direta com essas ações. Ou seja, o objetivo é a da apropriação do saber científico cumprindo a finalidade educativa da escola. As ações práticas podem acontecer na ou com a participação da escola, mas a centralidade curricular é trabalhar o conhecimento. Ou ainda, o efeito prático virá pela apropriação do conhecimento enquanto elemento essencial da formação humana para a qualidade de vida das pessoas e do ambiente. Um caminho inverso, ou seja, pelo conhecimento os sujeitos também 
estarão mais preparados para entender a realidade e prevenir os possíveis danos enquanto resultados de fenômenos naturais e das formas de organização social no espaço geográfico.

A escola existe para trabalhar com o conhecimento. Daí o desenvolvimento de metodologias de ensino-aprendizagem com essa finalidade, destacando-se as proposições já citadas neste texto, quais sejam, projeto de trabalho, aprendizagem baseada em problemas, estudo do meio, unidade temática. São proposições que se organizam para o estudo de um tema e desafiam professores e alunos para a construção social do conhecimento escolar em uma perspectiva de ensino-pesquisa.

Para oportunizar a reflexão aqui sugerida sobre o ensino-aprendizagem da Geografia Urbana uma ideia de tema pode ser a questão da cidade resiliente. A inspiração desse tema vem da campanha Construindo Cidades Resilientes indicada no Marco de Ação de Hyogo (2005-2015) e lançada em 2010 pela secretaria das Nações Unidade para a Redução do Risco de Desastres - UNISDR/ONU. (NAÇÕES UNIDAS, 2012)

Dentre os fatores de riscos nas cidades estão os relacionados com o crescimento da população urbana, ampliando a demanda de serviços e de ocupações de áreas sem o necessário planejamento territorial. Essa expansão urbana também ocorre sem a adequada fiscalização dos poderes públicos aliada com a precariedade de recursos mormente concentrados no âmbito federal. Esse contexto gera problemas quanto a gestão dos recursos hídricos, dos sistemas de drenagem e de resíduos sólidos, declínio dos ecossistemas, deterioração de infraestrutura promovendo emergências sanitárias, inundações, deslizamentos e outras formas de fenômenos naturais e ou sociais que ampliam as vulnerabilidades e a ocorrência de desastres.

Construir a resiliência implica em ações institucionais e comunitárias. Dentre as sugeridas pelo Marco de Hyogo pode-se destacar, considerando a abordagem aqui desenvolvida, as seguintes:

[...] conhecer os próprios riscos: identificar, avaliar e monitorar os riscos de desastres e melhorar os alarmes e alertas; construir conhecimento e sensibilização: utilizar conhecimento, inovação e educação para construir uma cultura de segurança e resiliência em todos os níveis. (NAÇÕES UNIDAS, 2012, p. 12).

A ideia de trabalhar os conteúdos escolares e no caso o exemplo de tematizar a cidade resiliente apresenta sintonia com essas ações sugeridas. O documento de Hyogo apresenta o que foi denominado como Dez Passos para Construir Cidades Resilientes. Essas orientações 
foram atualizadas pelo Marco de Sendai para Redução de Riscos e Desastres (2015-2030). Esses documentos globais figuram como possíveis fontes a serem consultadas, se necessário, quando do desenvolvimento das práticas didáticas.

Explicitada a origem da expressão Cidades Resilientes é o momento de aproximar esse tema para a prática de ensino-aprendizagem. Para esse exercício demonstrativo com a finalidade de situar e ampliar a reflexão aqui proposta, a sugestão é tratar o tema Construindo a minha cidade (pode ser o meu bairro) resiliente. A forma da unidade temática é uma das alternativas para o estudo. Fazemos essa escolha também para desenvolver os cinco momentos organicamente articulados da pedagogia histórico-crítica (SAVIANI, 1987 e 2005; AZAMBUJA, 2018). Vejamos então a seguinte simulação:

\section{$1^{o}$ momento - Prática social inicial}

Utilizando imagens de eventos naturais que possam ter produzido danos em áreas urbanas iniciar uma conversa com os alunos sobre o tema. Fazê-los expressar o seu conhecimento de senso comum, relacionando os problemas e porque ocorrem. E o que fazer para mitigar ou diminuir a vulnerabilidade de danos a partir de um olhar primeiro sobre o espaço urbano a ser estudado, podendo ser o da cidade onde a escola está situada ou de outras cidades.

\section{$2^{\circ}$ momento - Problematização}

Na sequência da mobilização do saber de senso comum desenvolvida no momento do resgate da prática social dos sujeitos organiza-se o momento da problematização. É o momento de ampliar a conversa e de estabelecer as interlocuções com o conteúdo de Geografia Urbana a ser estudado. Os recursos didáticos poderão ser ampliados com o uso de outras imagens/ vídeos e ou de um ou mais textos que podem ser, por exemplo, de notícias jornalísticas sobre o tema. Os itens do conteúdo são confirmados ou identificados nessa etapa do processo.

Nessas atividades de problematização poderá ou será necessário incluir uma reflexão inicial sobre conceitos que estão relacionados com o tema dos desastres naturais/ sociais. $\mathrm{O}$ risco de desastre está relacionado com as associações que podem ser feitas entre a existência da ameaça e a vulnerabilidade do lugar $X$ a capacidade de enfrentamento, ou seja, a resiliência. 
A ideia é fazer a reflexão conceitual relacionando com situações vivenciadas pelos alunos e ou no lugar onde vivem e está situada a escola, podendo ampliar para outras escalas geográficas ou outros lugares. Identificar, exercitar nessas atividades o olhar para a organização do espaço urbano, tematizando os diversos itens que darão forma ao conteúdo escolar, tais como, a infraestrutura urbana: pavimentação das ruas e avenidas, iluminação pública, esgotamento sanitário, arborização; equipamentos públicos de educação, saúde, lazer; uso do solo; zoneamento urbano; serviços como recolhimento e destino dos resíduos sólidos, dentre outros aspectos.

\section{$3^{o}$ momento - Instrumentalização}

A apropriação mais focada do tema de estudo e a definição coletiva dos itens do conteúdo a ser estudado é chegado então o momento do estudo-pesquisa propriamente dito. Os recursos didáticos ou fontes de estudo serão o livro didático, endereços virtuais (sites), outros livros, revistas, jornais. Ainda a possibilidade do trabalho de campo escolar a ser organizado, se o caso, com um planejamento específico.

Uma possibilidade didática poderá estar inspirada no desafio de organizar um plano de resiliência para a cidade (ou bairro). Constaria de um diagnóstico e avaliação dos riscos. Fazer uma identificação por meio de informações coletadas à campo e ou em outras fontes, tendo como referência os itens destacados como o conteúdo a ser estudado. Na sequência seria elaborado um plano de metas e ações para a resiliência da cidade (ou bairro). Para o desenvolvimento dessas atividades, a mediação do(a) professor(a) incluiria a organização de grupos e a distribuição de subtemas e atividades específicas, além, de orientar a organização dos resultados.

\section{$4^{o}$ momento - Produção (catarse)}

Esse é o momento da explicitação dos resultados na forma dos trabalhos escolares. As atividades de estudo-pesquisa realizadas no momento da instrumentalização serão expostas, podendo ocorrer de formas diversas, tais como: relatórios escritos, exposição de imagens comentadas, mapas, croquis e ou maquetes, gráficos. São atividades a serem realizadas individual e ou coletivamente conforme a organização dos grupos de trabalho definidos no processo. A opção pela elaboração de um plano de metas e ações para a cidade (ou bairro) resiliente pode ser uma das formas de exposição dos estudos curriculares. 
$5^{\circ}$ momento- Prática social

A prática social a ser referida após o desenvolvimento dos estudos significa identificar as mudanças de entendimento e de ação oportunizadas pela apropriação do conhecimento científico. Está suposto que o conhecimento mais qualificado da realidade qualifica também a cidadania e a atitude dos sujeitos para a vida. Não cabe a escola resolver os problemas urbanos que podem ter origem em desastres. Essa é uma tarefa da sociedade, envolvendo o público e o privado. Mas ao desenvolver a capacidade de coletar, organizar e interpretar as informações, os alunos, e os demais sujeitos da comunidade escolar estarão com certeza mais capacitados em contribuir com a resiliência de sua cidade ou bairro.

\section{CONSIDERAÇÕES FINAIS}

Ao projetar a renovação didática da Geografia um dos eixos de preocupação pode ser o de estabelecer a interação ciência, realidade e sujeitos. Para isso, os conteúdos do ensinoaprendizagem precisam ser trabalhados com significação histórica e social, o que implica relacionar a universalidade do conhecimento com os tempos e espaços de vivências das comunidades escolares. A ideia de trabalhar temas relacionados com a questão dos desastres naturais ou desastres com desencadeadores naturais oportuniza o exercício dessa perspectiva curricular.

A atualidade e necessidade social do tema são evidenciados pelo destaque efetivado por programas e ações de governos e ou de organismos nacionais e internacionais. Daí também a pertinência em articular conteúdos escolares de Geografia e ou de outros componentes curriculares da Educação Básica.

Conhecer conceitos e informações como destacados na primeira parte do texto é oportuno para projetar e realizar práticas de ensino-aprendizagem. As simulações elaboradas sobre o tema erosão e sobre o tema da cidade resiliente são demonstrativas e objetivam instigar o pensamento didático associados aos conteúdos geográficos. Outras simulações ou práticas podem ser elaboradas, abordando outros conteúdos da Geografia Escolar. A oportunidade e adequação ao momento e a realidade é uma atribuição docente na singularidade da sua escola. 


\section{REFERÊNCIAS}

AFONSO, Anice Esteves. Perspectivas e possibilidades do ensino aprendizagem em Geografia Física na formação de professores de Geografia. UFRJ/Instituto de Geociências, Departamento de Geografia, Programa de Pós-Graduação em Geografia, Rio de Janeiro, 2015.

AZAMBUJA, Leonardo Dirceu de. A Geografia do Brasil na Educação Básica: Uma didática para o ensino da formação socioespacial brasileira. Curitiba: CRV, 2018.

CASTRO, Antônio Luiz Coimbra de. Glossário de defesa civil: estudos de riscos e medicina de desastres. Brasília: MPO/Departamento de Defesa Civil. 2 ed. 1998.

Manual de planejamento em defesa civil. Vol. 1. Brasília: Ministério da Integração Nacional/ Departamento de Defesa Civil. 1999.

KOBIYAMA, Masato. et al. Prevenção de desastres naturais: conceitos básicos. Florianópolis: Ed. Organic Trading, 2006. 109 p : Il tabs.

MAGNONI JUNIOR, Lourenço, MAGNONI, Maria da Graça Melo e FIGUEIREDO, Wellington dos Santos. A contribuição da educação para a redução do risco de desastres e a resiliência no meio rural e urbano, IN.: MAGNONI JUNIOR, Lourenço e outros (Orgs.) Redução do risco de desastre e a resiliência no meio rural e urbano. São Paulo: Centro Paula Souza, 2017, p. 182-196.

MARCHIORI-FARIA, Daniela Girio; SANTORO, Jair. Gerenciamento de desastres naturais IN: TOMINGA, Lídia Keiko e outros. Desastres Naturais: conhecer para prevenir. São Paulo: Instituto Geológico, 2009, p. 161-178.

NAÇÕES UNIDAS. Como Construir Cidades mais Resilientes: um Guia para Gestores Públicos Locais. Genebra, novembro de 2012. Acesso em 25-03-2019:

https://www.unisdr.org/files/26462_guiagestorespublicosweb.pdf

SANTORO, Jair. Erosão continental, IN: TOMINGA, Lídia Keiko; SANTORO, Jair; AMARAL, Rosângela do. Desastres Naturais: conhecer para prevenir. São Paulo: Instituto Geológico, 2009, p. 53-70.

SAVIANI, Dermeval. Escola e democracia. 15. ed. São Paulo: Autores Associados, 1987.

Pedagogia histórico-crítica: primeiras aproximações. 9. ed. São Paulo: Autores Associados, 2005.

TOMINAGA, Lídia Keiko. Desastres naturais: Por que ocorrem? IN: TOMINGA, Lídia Keiko; SANTORO, Jair; AMARAL, Rosângela do. Desastres Naturais: conhecer para prevenir. São Paulo: Instituto Geológico, 2009, p. 11-23.

VALE, Jose Misael Ferreira. A contribuição da educação e da inovação tecnológica para a resiliência, In.: JUNIOR, Lourenço Magnoni e outros. Redução de riscos de desastres e a resiliência nomeio rural e urbano. São Paulo: Centro Paula Souza, 2017, 132-137.

Marco de ação de Hyogo 
http://www.defesacivil.pr.gov.br/arquivos/File/Marco/MarcodeHyogoPortugues20052015.pdf Marco de ação de Sendai

http://www1.udesc.br/arquivos/id_submenu/1398/traduzido_unisdr__novo_sendai_framewo rk_for_disaster_risk_reduction_2015_2030_portugues_versao_31mai2015.pdf

UN-ISDR - http://www.unisdr.org/who-we-are/what-is-drr 